\title{
Protesto indígena na Colômbia: $O$ caso dos indígenas caucanos ${ }^{1}$.
}

Elizabeth del Socorro Ruano Ibarra ${ }^{2}$

\section{Resumo}

Práticas de protesto indígena na Colômbia constituem o objeto empírico desta pesquisa. Metodologicamente são estudadas as matérias jornalísticas, produzidas por jornais de reconhecida importância no país, com ocasião dos eventos do protesto indígena realizados no período compreendido entre outubro e novembro de 2008. A repetição periódica dessas práticas, corriqueira no senso comum, é problematizada como uma estratégia indígena para conferir-se espaço na historicidade nacional. Sua constituição em noticia veiculada nos diferentes meios de comunicação permite-lhes conquistar a atenção da sociedade envolvente. História e território, operadores simbólicos da identidade étnica, convocam à mobilização e se acionam durante esses eventos de protesto.

Palavras chave: indígenas Nasa, práticas políticas indígenas, protesto indígena, Colômbia.

\section{Introdução}

Geralmente o debate acadêmico sobre a mobilização indígena toma como ponto de partida a análise das organizações ou movimentos indígenas de maior abrangência, caráter regional ou nacional. Nessa ordem ancorou-se a idéia de que a existência de uma sólida organização de caráter nacional indicaria maturidade política. Alguns estudos observaram a dificuldade de constituir e/ou manter essas organizações, colocaram em evidencia as tensões e conflitos, e associaram-nas com enfraquecimento do processo de luta indígena. Outras análises indicaram que as conquistas alcançadas pelos indígenas podem ser explicadas no contexto de uma dinâmica governamental de maior apertura diante da questão étnica.

Na Colômbia vidas indígenas são sacrificadas nos processos locais de protesto diante do governo nacional. A agenda indígena de reclamações foca-se, quase sempre, na exigência do cumprimento de compromissos assumidos pelos governos de turno. Em resposta estratégias governamentais orientadas à mitigação do protesto indígena são ativadas. Nesse contexto, é corriqueira a criminalização do protesto indígena, associando-o com terrorismo. A violência exercida pela força pública em contra dos indígenas justifica-se argumentando a infiltração de forças alteradoras da ordem nessas mobilizações sociais.

Não obstante, as práticas, estratégias e instrumentos de reclamação indígena no sul da Colômbia indicam a existência de um processo social de contestação das ações e/ou omissões governamentais. Nossa reflexão assume como fio condutor o pionerismo exercido pelos indígenas $\mathrm{Nasa}^{3}$ na reivindicação de direitos. É privilegiada a análise dos eventos de protesto indígena acontecidos entre outubro e novembro de 2008 no Departamento de Cauca ${ }^{4}$. Essa região administrativa possui aproximadamente $3 \%$ da população colombiana. Em Cauca encontram-se nove povos ancestrais, localizados em

\footnotetext{
${ }^{1}$ Trabalho apresentado na $27^{\circ}$ Reunião Brasileira de Antropologia. Belem (PA) 1- 4 de agosto de 2010.

2 Doutoranda no Centro de Pesquisa e Pós-Graduação Sobre As Américas - CEPPAC. Universidade De Brasília - UnB. Bolsista PEC-PG elizabethruano@ gmail.com

${ }^{3}$ Autodenominação que começou a ser usada a partir da década de 1980, surge da palavra nasa yuwe cujo significado poderia traduzir-se como "povo-território". Anteriormente eram conhecidos como Páez, nomeação espanhola que surgiu a partir do nome de um cacique indígena.

${ }^{4}$ Unidade político-administrativa colombiana, similar ao Estado no Brasil.
} 
87 resguardos indígenas ${ }^{5}$. Os indígenas caucanos alcançam uma densidade populacional equivalente a $21,5 \%$ da população caucana. Aproximadamente $18 \%$ da população indígena colombiana está localizada no Estado de Cauca.

Mapa Localização do Estado de Cauca na Colômbia.

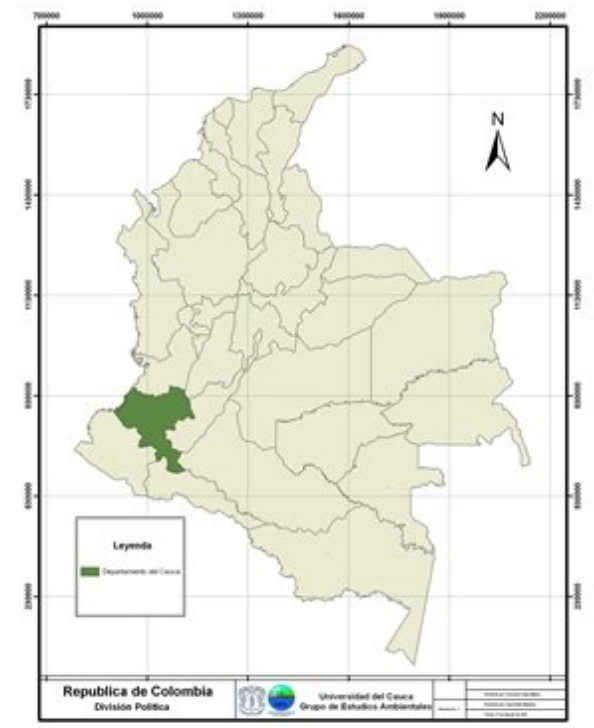

Fonte: Grupo de Estudios Ambientales - GEA, Universidad del Cauca.

A análise apresentada a seguir corresponde a um recorte de uma pesquisa em andamento ${ }^{6}$. A decisão de conferir-lhe centralidade neste estudo aos eventos de protesto do período em questão surge diante de um aparente desinteresse acadêmico por esse fato. O dinamismo observado durante os eventos de protesto indígena no Sul da Colômbia indica que não há enfraquecimento da luta indígena, apesar das tensões que as organizações indígenas possam estar sofrendo, principalmente de aquelas de ordem nacional. Nos avanços preliminares da pesquisa citada identificou-se que as práticas de protesto indígena pelas quais nos interessamos são atualmente uma especificidade dos indígenas caucanos ${ }^{7}$.

\footnotetext{
${ }^{5}$ Criados mediante cédula real da coroa espanhola, os resguardos expressam o movimento de redução dos territórios indígenas. Sua vigência foi ratificada na Lei número 89 de 1890, reconhecendo o direito de propriedade das comunidades indígenas sobre as terras que ocupam, sendo elas inalienáveis (MACHADO, 1986).

${ }^{6}$ Análise comparada do protesto indígena na Colômbia e no Brasil, no âmbito da tese de doutorado no CEPPAC-UnB.

7 "En Icanh [Instituto colombiano de Antropologia e Historia] no tenemos ninguna investigación sobre movimiento sociales indígenas ni tampoco sobre las protestas y bloqueos de carreteras [...] la práctica del bloqueo se presenta particularmente entre organizaciones del suroccidente colombiano, y en ninguna otra parte del país. Y a mi modo de ver es en esta región y particularmente en el Cauca en donde existe aún un movimiento que promueve agendas propias. En el resto del país lo que ha hecho el estado con sus políticas multiculturales es copar las agendas de las organizaciones regionales e incluso, las de la ONIC". Depoimento por e-mail da Ph.D. Margarita Chaves Coordenadora do Grupo de Antropologia Social do ICANH, 15/04/2010, grifos nossos).
} 
Quais elementos explicativos para dita situação? Por que os indígenas do Departamento de Cauca conseguiram aprimorar sua prática de protesto? Questiona-se a continuidade dos eventos de protesto indígena num contexto nacional que há décadas possui um mandato constitucional, que diz respeito ao direito e respeito pela diferença étnica. Indagamos também se ditas práticas de protesto podem indicar um "modo diferente" de fazer política num cenário nacional que não consegue operacionalizar os preceitos constitucionais. O ensaio tenta dar conta do desafio a partir de uma breve contextualização histórica do protesto indígena, uma descrição analítica do protesto indígena realizado entre outubro e novembro de 2008 e conclui com a apresentação das considerações finais.

\section{Breve contextualização histórica}

$\mathrm{Na}$ margem da história oficial colombiana encontram-se indicações que demonstram que a preocupação em matéria de protesto/reivindicação dos direitos das coletividades indígenas não é um fenômeno recente. Os eventos que ficaram visíveis na década de 1970 foram resultantes de um contexto, de um processo de luta antigo, historicamente construído. Antes disso, internamente e isoladamente os povos indígenas desenvolveram seus processos de luta, não obstante, o contexto sócio-político dessa década, potencializou a expansão do caráter organizativo e político outorgando-lhe maior projeção e visibilidade (GÓMEZ, 2000). O caso dos indígenas Nasa permite afirmar que seu processo de reivindicação indígena é cumulativo. Nessa trilha, não seria equivocado tentar analisá-lo a partir da perspectiva da longa duração. Nos dados históricos marginalizados encontra-se, antes de tudo, raízes e continuidades nessa luta que conquista mudanças, porém lentamente.

Nessa ordem, destaca-se que apesar das críticas condições de dominação do período colonizador, a defesa dos territórios indígenas constituiu-se no eixo articulador da dinâmica de luta. Mediante processos de negociação ${ }^{8}$ assumidos pelos caciques índios, o povo Nasa obtive a autorização da coroa espanhola para a criação de resguardos indígenas. Estes, diferentemente de outros constituídos com anterioridade, adotaram a forma de escudo de proteção, da língua nativa e dos costumes. Não se tratou somente de uma demanda por terra, a reivindicação de resguardos indígenas diferenciados constituiu-se no iniciou de uma prática de defesa territorial diante da colonização espanhola. A constituição dos resguardos tinha implícita a intencionalidade de proteção e preservação do sistema próprio de organização e reprodução social indígena. Essa dinâmica indígena explicaria porque o Resguardo e o Cabildo ${ }^{9}$, instituições de origem colonial, sofreram o que Gómez (2000) denominou " $r e$ funcionalização intra-étnica". Isto é, essas instituições coloniais atualmente constituem distintivos étnicos, graças à operacionalização de formas de resistência cultural e estratégias políticas deliberadas.

As práticas indígenas de defesa territorial são diversas e coerentes, mas nem sempre os resultados alcançados são conforme esperados. É nessa direção que se documenta a participação ativa dos indígenas Nasa nas batalhas livradas em favor da

\footnotetext{
${ }^{8}$ Gómez \& Ruiz. Los paeces gente territorio: metáfora que perdura. Popayán: Universidad del Cauca. 1997.

9 Opera como um foro, viabilizando a tomada de decisões nas populações indígenas. Em 1988 foi reconhecida como instituição legal de caráter especial, recebendo o direito de posse coletiva do seu território e autonomia para regular-se com princípios, valores e tradições culturais próprios.
} 
independência. A promessa de libertação dos territórios ancestrais do mecanismo fragmentador e do sistema tributário imposto por Espanha motivou a vinculação indígena. Não obstante, após a independência o sistema de impostos foi restituído e se promoveu a liquidação dos territórios indígenas sobre a justificativa de outorga-lhes cidadania.

Posteriormente ficaram expostos às consequiências da violência entre os nascentes partidos políticos. $\mathrm{O}$ enfrentamento armado entre o Partido Conservador e o Partido Liberal introduziu a existência de duas forças de poder local, de um lado os "azuis" simpatizantes do Partido Conservador e do outro, os "vermelhos" simpatizantes do Partido Liberal. Os indígenas não foram alheios a essa lógica, essa divisão dificultou o processo de organização e reclamo indígena. Mas não extinguiu a re-construção de um referencial de identidade a partir do reconhecimento de um passado comum e de uma tradição milenária.

No momento republicano, destaca-se como prática política indígena a recuperação de documentos históricos nos quais consta a propriedade dos resguardos outorgada aos indígenas pela coroa espanhola. Tratou-se de uma pesquisa exaustiva liderada pelos indígenas para identificar a localização física desses documentos, pois, sua existência até então era somente respaldada pela oralidade indígena. Lideranças indígenas afirmam que a tentativa de recuperação desses documentos foi permanentemente desafiada pelos latifundiários. Lideranças indígenas relatam que aconteceram mortes indígenas, na tentativa de desanimar essa empreitada ${ }^{10}$.

A importância dos documentos escritos explica o surgimento do livro "Los pensamientos de un indio que se educó dentro de la selva colombiana" de autoria do indígena Manuel Quintin Lame. Escrito durante a década de 1900 foi somente publicado em 1971. A importância deste livro não é apenas atribuída pelo fato de ser uma obra pioneira na escrita indígena, pois conseguiu constituir-se como mecanismo de difusão da luta indígena. As narrativas documentadas nesse livro viraram um insumo fundamental para a política indígena atual. Não entraremos no debate em torno da figura de Quintin Lame, limitamo-nos apenas a introduzir, em nota de rodapé, algumas variações dessa polêmica ${ }^{11}$. Contudo, a centralidade de Quintin Lame na luta indígena pode ser constatada na influência do seu pensamento no surgimento do Conselho Indígena Regional del Cauca - CRIC $^{12}$ em 1970 e nas políticas indígenas adotadas nesse momento.

\footnotetext{
${ }^{10}$ Entrevista realizada com um líder indígena, em Silvia Cauca, em 27 de novembro de 2007 (RUANO, 2008).

11 Alguns pesquisadores afirmam ter existido um movimento indígena colombiano armado. Esta afirmação poderia ser resultante da associação dos seguintes fatos: a) em 1960 aconteceu um evento de levantamento em armas, um desdobramento transitório na luta liderada por Quintin Lame, uma revolta que não superou uma semana de duração, b) em 1980, Lame já tinha morrido (1967), surgiu um movimento armado que se apropriou do nome dessa liderança indígena. Segundo Castillo (2007) esse movimento armado não foi liderado por indígenas. Apesar do discurso desse movimento armado indicar compromisso com a luta pela terra não conseguiu desfrutar do apoio dos indígenas, menos ainda das organizações indígenas constituídas na época. Segundo Rappaport (2000:117) as ligações entre o movimento indígena e esse movimento armado eram tão tensas que "foi acusado de assassinar vários ativistas indígenas".

12 Organização indígena que reúne $90 \%$ dos povos indígenas do Estado de Cauca. Representa 115 Cabildos e 11 associações de Cabildos indígenas. "É reconhecida como Autoridade Tradicional, é uma entidade pública de caráter especial [...] no CRIC são definidas políticas e se projetam fazeres no econômico, social, cultural, territorial, ambiental, jurídico entre outros [...] seus conselheiros são nomeados para períodos de dois anos" www.cric-colombia.org
} 
Na apresentação da agenda do movimento indígena em 1971, o CRIC afirmou estar retomando as demandas defendidas desde 1920 por Quintin Lame: recuperação de terras e ampliação das reservas indígenas; abolição do terraje $^{13}$; defesa da história, da língua e os costumes; formação de professores indígenas; implementação de um processo de educação próprio e fortalecimento dos cabildos. A agenda reivindicadora liderada pelo CRIC tem como eixo vertebral a noção recuperação de terras. Essa categoria discursiva foi adotada para contestar a denominação invasão, com a qual era desqualificada a mobilização indígena de luta pela terra. À luz da denominação recuperação de terras legitima-se o processo de recuperação do território ancestral, perdido mediante mentiras e abusos. Nesse momento, os títulos de propriedade recuperados anos atrás são esgrimidos como instrumentos de luta legal.

No contexto do processo de recuperação de terras, entre 1971-1974, foram recuperados 10.000 hectares para os territórios indígenas. Este resultado se comparado com 8.000 hectares conseguidos em dez anos de reforma agrária reforçou a prática de recuperação territorial adotada pelos indígenas, apesar de implicar em sacrifício de vidas, persecução e criminalização do movimento indígena. Na década de 1980 os acontecimentos da luta indígena colombiana a ser destacados estão intimamente relacionados com os avanços alcançados pela liderança do CRIC, organização de caráter regional. Sua influência foi maior nas regiões aonde ainda persistia o terraje e onde os indígenas não tinham terras de resguardo, isto é, naquelas regiões aonde o conflito territorial era maior.

Apesar do dinamismo gerado pelo CRIC apareceram também insatisfações, algumas geradas pela crescente burocratização, pelo controle exercido pelos não indígenas e pela pouca participação das autoridades tradicionais na tomada de decisões. Observe-se que as tensões surgidas estão associadas à legitimidade da representação: autoridades tradicionais versus novas lideranças e/ou organizações locais versus organizações de caráter nacional. Na década de 1980 surgiram na Colômbia novas organizações indígenas. Em 1982 nasceu a Organização Indígena Nacional de Colômbia - ONIC, organização de caráter nacional e em 1988 surgiu o Movimento de Autoridades Indígenas de Colômbia - AICO.

Essas tensões segundo Gomez (2000:150) poderiam explicar-se a partir de uma concepção dual do exercício do poder indígena contemporâneo. Para ele "o exercício do poder a nível gremial [CRIC, ONIC, AICO] não é similar ou igual ao que é exercido internamente nas etnias". As organizações regionais e nacionais indígenas adotaram mecanismos para relacionar-se - negociar/concertar- com o aparelho governamental (SÁNCHEZ, 1990). Entanto as organizações indígenas adotam um perfil negociador, dando recesso às velhas formas de luta, nos âmbitos locais os povos indígenas mantiveram a luta pela reconstituição da identidade étnica, valendo-se em alguns casos da ameaça ou do uso da força.

Mediante a Constituição Política de 1991, Colômbia se reconheceu como uma nação pluri-étnica e multicultural. A reforma no corpo jurídico estimulou novas contradições e conflitos. Vejamos as motivadas pela Lei de transferências ${ }^{14}$, suas

\footnotetext{
${ }^{13}$ Sistema de trabalho mediante o qual um latifundiário usava o trabalho indígena e, em troca, o indígena usava um pedaço pequeno de terra dentro da fazenda. A forma generalizada de pagamento do "terraje" é a mão-de-obra indígena.

${ }^{14}$ Lei $n^{\circ} 60 / 93$, modificada pela Lei $n^{\circ} 715 / 07$, estipulou que as reservas indígenas, do mesmo modo que, os Departamentos e Municípios seriam beneficiarias e responsáveis pela gestão e administração dos recursos de Transferências, outorgados proporcionalmente à quantidade populacional. Estabelece os
} 
disposições levaram aos territórios indígenas colombianos a ser abruptamente inseridos num processo de gestão de orçamento público. Nesse particular uma liderança indígena declarou que "a inexperiência na administração e execução do dinheiro público trouxe $\mathrm{s}$ traumatismos internos, em resposta surgiram os planos de vida"

Apesar de esses planos terem surgido como uma ferramenta própria para decidir o futuro, de maneira autônoma e focando suas demandas, na prática, operam similarmente aos planos que, por lei, constroem os governos municipais e estaduais ${ }^{16}$. Há quem afirme que a gestão do plano de vida converteu o cabildo indígena numa instância burocratizada e paquidérmica, que centraliza a tomada de decisões e retarda as ações. Aliás, a introdução da remuneração, com dinheiro público, das funções comunitárias até então ad honorem, teria estimulado o aparecimento de práticas clientelistas. Não obstante, a administração de investimentos públicos pelos cabildos indígenas permitiu desdobramentos positivos, como o desencadeamento de experiências e lições importantes no campo da saúde, a educação e projetos produtivos.

Para concluir este subtítulo afirma-se que os indígenas colombianos têm reivindicado seus direitos há muito tempo embora a história oficial e os estudos sociais empenharam-se em relegá-lo a épocas relativamente recentes ${ }^{17}$. Esta rápida e seletiva contextualização histórica tentou colocar em evidência um processo de protesto social cumulativo liderado pelos indígenas. Em diante, neste ensaio, a análise se fundamenta na problematização das práticas de reclamo indígena com destaque do contexto no qual foram produzidas. Ressalta-se que o protesto indígena permitiu que velhas reclamações conseguissem superar as divisas locais e gerar, quando menos, incômodo nas instâncias nacionais de tomada de decisão.

\section{Protesto indígena: os eventos de outubro e novembro de 2008}

Neste subtítulo destaca-se a sequencia de quatro momentos no ciclo do protesto indígena no período em questão. O poder indígena foi demonstrando na estruturação dos seguintes fatos: convite formal ao presidente Uribe, bloqueio da estrada panamericana $^{18}$, assembléia e marcha nacional. O pano de fundo do protesto foi à comemoração oficial dos 512 anos do descobrimento da América. Nessa lógica, os indígenas lançaram a campanha "resistência e luta pela vida e a dignidade". Essa

setores alvo e as porcentagens de recursos nas que deve distribuir-se a transferência: 58,5\% educação, $24,5 \%$ saúde, propósito geral 17,4\% (saneamento básico, gastos de funcionamento, cultura, esporte e recreação); $10 \%$ restante: $7 \%$ esporte e recreação, e $3 \%$ cultura.

${ }^{15}$ Entrevista realizada em 10/12/2007 (RUANO, 2008, p. 71).

16 Concebidos no âmbito do processo de descentralização e da consolidação da eleição popular de prefeitos municipais e governadores estaduais. Foram pensados como uma ferramenta para a consolidação do voto programático. Isto é, os governantes eleitos converteriam suas propostas de campanha eleitoral - programas de governo-, em planes de desenvolvimento que posteriormente se transformariam em leis municipais - Acordos- ou departamentais - ordenanças-, por tanto de obrigatório cumprimento.

${ }^{17}$ Por exemplo, na análise comparativa do movimento indígena equatoriano e colombiano a primeira etapa do movimento indígena equatoriano corresponde aos "levantamentos" indígenas durante a colonização espanhola. Já no caso colombiano se parte de Quintin Lame no período 1910-1920, e afirmase que essas lutas indígenas teriam fracassado (CASTILLO \& CAIRO, 2008).

${ }^{18}$ Importante estrada que permite a integração do Centro e Norte do país e comunica a Colômbia com o Equador. Não conhecemos estudos sobre o custo econômico gerado por esse mecanismo de protesto, não obstante, a mídia nacional geralmente destaca que as altas perdas econômicas decorrentes. 
empreitada dos indígenas começou com a difusão do convite formal feito ao presidente Uribe. Nessa comunicação expressaram:

Los pueblos indios, mestizos y afrodescendientes del Cauca y del suroccidente colombiano del campo y de la ciudad, avanzamos en unidad haciendo oír nuestra voz y nuestro sentir ante la Nación colombiana y ante la comunidad internacional.

Vamos en la Minga de Resistencia Social y Comunitaria del Suroccidente Colombiano caminando la senda de los mayores para exigirle al Estado y al gobierno nacional que cumpla el mandato constitucional de reconocer nuestra existencia como pueblos, sectores sociales y comunidades organizadas y recordar la deuda que mantiene el Estado nacional con los sectores organizados a través de acuerdos y convenios firmados en procesos de movilización pacífica.

Señor presidente $[\ldots]$ demandamos su presencia el día 14 de octubre de 2008 en la María Piendamó $^{19}$ [...] para que le cuente a nuestra gente, de frente al mundo, cuándo su política tomará la ruta que permita garantizar los derechos fundamentales de todos los colombianos, los que seguimos reclamando por ser derechos inalienables: a la tierra, al agua, al trabajo, a la vivienda digna, a la alimentación y al ambiente sano (COLÔMBIA, 2008, p. 2).

A carta é dirigida em representação de um coletivo social abrangente, numa clara tentativa de superar as dicotomias que distanciam/separam segmentos sociais marginalizados: rural/urbano; camponeses/indígenas; afro-descentes/indígenas; minorias étnicas/mestiços. Nessa perspectiva entendemos a adoção da palavra "minga ${ }^{20 "}$ na nomeação desse ato de protesto. Esse termo, no contexto desse discurso reivindicador, traz à superfície a existência de articulação entre vários segmentos sociais. A comunicação demanda explicações em relação à garantia dos direitos constitucionais no âmbito da política "segurança democrática" do governo Uribe.

Essa política militar tem sido crítica para os movimentos sociais colombianos. No tocante aos indígenas caucanos, as tensões acirraram-se quando com ocasião da edição número 192 do "conselho comunitário ${ }^{21}$ " realizado em 15 de março de 2008 na capital do Estado de Cauca, o presidente Uribe autorizou publicamente as autoridades militares a fornecer "recompensas ${ }^{22 "}$ para facilitar a identificação das lideranças

\footnotetext{
19 Território indígena localizado ao norte de Cauca, em outubro de 1999 foi declarado "território de convivência pacífica", representando um espaço onde a sociedade civil se constitui em ator válido no processo de solução negociada do conflito armado. A iniciativa propôs quatro temas centrais de discussão: 1) cumprimento dos acordos do governo central; 2) reforma agrária; 3) meio ambiente e diversidade; 4) direitos econômicos, sociais e culturais e vitimas direitas da guerra. O território localizase sobre a estrada pan-americana, pela sua localização estratégica, é nesse espaço da estrada que os indígenas geralmente realizam o bloqueio da estrada.

${ }^{20}$ Provém do quéchua minka, com a qual as comunidades andinas denominavam o trabalho coletivo em benefício da comunidade indígena. Na Colômbia, a palavra minga é usada para referir trabalhos comunitários entre parceiros, não é remunerado, e procura a ajuda mútua dos envolvidos. Essa denominação assume forte conteúdo político, sempre que usada, no contexto da luta territorial, implicando a junção de força indígena diante do poder dominante.

${ }^{21}$ Trata-se de uma ferramenta de gestão pública institucionalizada pelo governo Uribe, opera mediante reuniões regionais com a presença do presidente e dos ministros. Nesse espaço busca-se estudar e resolver os problemas expostos pelos cidadãos que participam, o vento é transmitido pela televisão pública. A seleção dos participantes, a atenção a determinadas denúncias e o descaso para outras são fatos criticáveis. Em 2010 foi proibida a transmissão televisiva desses eventos em atenção a uma ordem judiciária que denuncia a relação clientelista entre esses conselhos e a campanha eleitoral presidencial em curso.

${ }^{22}$ A política de "seguridade democrática" defende o fortalecimento aramado e a presença militar em todo o território nacional, ancora-se em estratégias acusadas de atentar contra as liberdades individuais e a
} 
indígenas comprometidas com a recuperação de terras. Esse antecedente é chave para explicar o surgimento da "Minga de Resistencia Social y Comunitaria".

Em 14 de outubro de 2008, no território La Maria, uma multidão aguardou a chegada do Presidente. Uribe não compareceu ao chamado, ato seguido, os indígenas acionaram o bloqueio da estrada pan-americana. Mediante essa prática os indígenas exigiram a materialização do compromisso governamental no tocante à expropriação de aproximadamente 200 mil hectares de terra de propriedade das usinas açucareiras. $\mathrm{O}$ protesto indígena foi repelido com intervenção policial, nesse confronto dois indígenas perderam a vida. De outro lado, um policial, acusado de infiltrar-se no território indígena La Maria, foi "castigado" conforme a tradição indígena, sofrendo lesões físicas graves $^{23}$.

Diante desses fatos, na mídia nacional, o presidente Uribe defendeu o agir da força pública argumentando infiltração subversiva no protesto indígena. Uribe descartou a responsabilidade da força armada estatal nas mortes dos indígenas. Posteriormente, à difusão de vídeos, realizados pelos indígenas, confirmou a responsabilidade de um policial na perda da vida dos dois indígenas ${ }^{24}$. A divulgação dos vídeos em rede nacional implicou numa denuncia de importante magnitude. As imagens contidas nos vídeos lembram o enfrentamento entre David e Golias, de um lado a força pública armada dos mais imponentes aparelhos, do outro os indígenas defendendo-se com bengalas de mando ${ }^{25}$, pedras e madeiros.

A partir dessas imagens de denuncia os indígenas exploraram os contornos de ordem política e dela serviram-se como alavanca para criticar o governo Uribe e sua política. Nesse nível da disputa política as palavras tanto quanto as ações constituíram meios de confronto. No debate público, veiculado pela mídia, novas ações e palavras orientaram-se à demonstração de legitimidade no exercício do poder político. As imagens dos indígenas repelidos pela força pública, em evidente desvantagem, permitiram chamar a atenção da opinião pública e legitimar o protesto indígena. Simultaneamente, o discurso governamental apelou à consciência nacional, lembro-o da causa comum e prioritária: a luta contra o terrorismo. Nessa lógica todos os colombianos estão endividados com a força pública. Desse modo justifica-se o fato dos policiais terem atirado contra os indígenas, as multidões são ameaçadoras da ordem, pois constituem um cenário potencial a ser aproveitado pelo terrorismo.

Decorrente da campanha informativa veiculada pelos indígenas na mídia e na internet $^{26}$ surgiram manifestações de apoio à reivindicação indígena. A seguinte matéria, ironicamente intitulada "mal ejemplo indígena" dá conta dessa situação:

democracia: "criação de redes de cooperantes [informantes]"; "fornecimento de recompensas a informantes" e "soldados camponeses".

${ }^{23}$ Cinco lideranças indígenas - dois conselheiros do CRIC, um governador indígena, dois integrantes da guarda indígena-, foram processados judicialmente por "seqüestro e lesões graves" contra esse policial. O tribunal indígena alega que sua ação enquadra-se nos princípios de justiça própria dos territórios indígenas.

${ }^{24}$ La encrucijada de los indígenas. Revista Semana, Colômbia, 22/10/2008.

${ }^{25}$ A partir do final da década de 1980 o CRIC promoveu a recuperação do ritual de "refrescamento das bengalas de mando" o qual marca simbolicamente o inicio do ano político no Cabildo Indígena. No processo de re-significação étnica as "bengalas de mando" simbolizam a "resistência pacifica" dos povos indígenas no contexto de conflito armado colombiano. As bengalas de mando identificam simbolicamente as autoridades tradicionais e os integrantes da "guardia" indígena. A última é uma instituição ancestral de defesa territorial, atualmente é potencializada como mecanismo de resistência não armada.

26 A "minga" informativa foi liderada pelo Sistema de Comunicação para a Paz, integrado 138 rádios comunitárias e 30 rádios indígenas. Não há dados que indiquem uma experiência nacional similar à 
El presidente Uribe dice mentiras [...] Ahora lo estamos viendo con la marcha de protesta indígena [...] Después de haber dicho que era "una infamia" acusar a la Policía de abrir fuego contra la marcha, y de haber conminado a los indígenas a "pedir perdón" [...] el Presidente salió en televisión con todos sus generales y ministros [...] a reconocer que sí: que la Policía sí había disparado [...] Y luego vino ya no sólo la negación en redondo de la historia, sino la mentira frontal para justificar que se siga repitiendo la historia: la acusación a la minga indígena de ser inspirada y dirigida por "terroristas" [...] Por lo visto los indios, además de latifundistas (lo fueron: todo lo que hoy se llama América era suyo), son mercenarios. Y terroristas, claro. El presidente Uribe y su Ministro saben que eso es una falsedad. Saben que las organizaciones y los cabildos indígenas -del Cauca, del Huila, del Tolima, de la Sierra Nevada- son los únicos que en este país se han enfrentado al terrorismo [...] Por eso, porque su resistencia es pacífica y sus reclamos son justos, hay que calumniar a los indígenas llamándolos terroristas cuando organizan marchas de protesta. Revista semana, Colômbia, 25/10/2008, grifos nossos.

Afirmou-se ainda que "está desapareciendo el arreglo constitucional [reforma constitucional de 1991] que habíamos logrado con los pueblos indígenas, un acuerdo del que nos sentíamos tan orgullosos los colombianos"27. A repressão contra os indígenas colombianos também foi criticada internacionalmente, a mídia colombiana difundiu duas cartas provenientes do Parlamento Europeu e do Sindicato Canadense de Trabalhadores públicos ${ }^{28}$. Esse contexto desfavorável à política promovida pelo presidente Uribe explica porque o governo retrocedeu na sua tentativa de negligenciar o potencial político do protesto indígena ${ }^{29}$. No inicio da disputa o governo afirmou que não cederia a pressões estimuladas pelo terrorismo. Apesar da criminalização da empreitada indígena, em 2 de novembro de 2008, o presidente Uribe e sua equipe de ministros reuniram-se, durante seis horas, com 20.000 indígenas em La Maria.

Sem êxito, o presidente Uribe propôs que dito encontro acontecera na capital caucana, Popayán. A escolha de um território indígena, governados por "princípios, valores e tradições culturais próprios", como sede do evento estava carregada de um peso simbólico. Lograr o deslocamento do presidente até La Maria era uma das conquistas políticas a ser alcançada pelo protesto indígena. Nesse sentido, diante da tentativa de mudança do local de encontro os indígenas afirmaram que, casso essa

dimensão da articulação alcançada pela rede construída pelos médios alternativos com ocasião da marcha indígena. Multitudinario congreso indígena en el camino. Inter Press Service, 15/09/2008.

${ }^{27}$ Retrocede política de gobierno frente a indígenas. Revista semana, Colômbia, 15/09/2008

${ }^{28}$ Eurodiputados, indignados por "graves violaciones a derechos indígenas y sindi cales". Revista semana, Colômbia, 23/10/2008 e Sindicatos de Canadá le envían carta a Uribe. Revista semana, Colômbia, 05/11/2008.

${ }^{29}$ Protestos anteriores não tinham conseguido maior impacto. As "capturas massivas", eixo central da política de "seguridad democrática", têm sido especialmente problemáticas para os indígenas e geraram vários protestos públicos: Julho de 2004, Tacueyó Cauca, captura de Sergio Sascué, acusado de ser o motorista da chefia das FARC, os protestos denunciaram que o capturado nem sabia dirigir; dezembro de 2004, Sierra Nevada de Santa Marta, diante da captura de 26 indígenas Kankuamo acusados de rebelião; Maio de 2005, Jambaló Cauca, captura de 10 lideranças indígenas acusados de serem colaboradores de atentados terroristas; Agosto de 2005, Santader de Quilichao, os indígenas protestaram em Plaza pública pela acusação "los indígenas son auxiliares de la guerilla" realizada por Hernando Pérez, Comandante do Exercito Nacional; dezembro de 2005, Chaparral Tolima, pela captura de Fernando Martinez acusado de rebelião. Em nenhum destes casos foram apresentadas provas que suportassem as capturas, mesmo assim, em todos os casos os indígenas permaneceram mais de um mês na cadeia. La seguridad democrática y los indígenas. Revista semana, Colômbia, 02/10/2008. 
demanda não fosse aceita, marchariam até a capital do país. Mediante essa ameaça colocava-se a possibilidade de acontecer um fato sem precedentes: o protesto indígena extrapolaria as fronteiras locais.

A assembléia entre indígenas e o governo aconteceu de acordo às especificações determinadas pela organização indígena. $\mathrm{O}$ evento foi transmitido pela emissora televisiva institucional. Os indígenas apresentaram as seguintes demandas: i) a necessidade de preservar a autonomia dos territórios indígenas no contexto de guerra interna; ii) a revisão da distribuição da terra e da legislação usos; iii) exigiram o cumprimento dos acordos antigos assinados pelo governo nacional; iv) demandaram respeito pela declaração das Nações Unidas sobre os povos indígenas; v) rejeitaram o tratado de livre comercio ${ }^{30}$.

Diante do primeiro ponto o presidente Uribe propôs a criação de "enlaces" entre as forças militares e os indígenas. Essa resposta governamental resultou quando menos ingênua, pois é bem sabido que no conflito armado colombiano a colaboração com a força pública é severamente castigada pelos grupos armados à margem da lei. Não obstante, diante da negativa dos indígenas de aceitar a presença da força pública nos seus territórios o presidente Uribe destacou que "nenhuma porção do território nacional pode estar vedada para a força pública, sendo esta orientação constitucional". Ou seja, a política de "seguridad democrática" não é respeitosa da autonomia dos territórios indígenas.

No segundo ponto, o presidente mostrou-se a favor da consulta sobre usos do solo, não obstante, chamou a atenção para que essa reivindicação não fosse usada para dilatar projetos em andamento. Diz ainda que, não pode haver território sem presença militar e que o subsolo da nação não pertence aos grupos étnicos. Sobre o terceiro ponto, relacionado com o problema mais antigo, o conflito por terra, o presidente pediu a seu ministro de agricultura "examinar o modo de apoiar com maior intensidade projetos produtivos". No repertório governamental a demanda indígena por território é autonomia é encarada a partir da dinâmica "desenvolventista", preocupada somente com o crescimento econômico.

No quarto ponto, sobre a declaração das Nações Unidas, o governo propôs assinar uma "declaração unilateral" que indique que Colômbia comparte os princípios da declaração, mas que os pontos nela defendidos não são compatíveis com a Constituição Nacional. Finalmente, no tocante ao tratado de livre comércio, o presidente afirmou que as multinacionais não representam ameaça para os territórios indígenas ${ }^{31}$.

Poder-se-ia afirmar que na assembléia entre os indígenas e o presidente Uribe houve um "não diálogo". Os indígenas afirmaram que "o mandatário nacional dedicouse a defender-se e não a responder e propor verdadeiras soluções para os problemas denunciados". O presidente Uribe diz que "é melhor contar com um governo que diz o que pensa [...] este governo não é mentiroso. Imaginem um governo, que por sair da saia justa, venha a comprometer-se com obrigações que não se podem cumprir ${ }^{32,}$.

\footnotetext{
${ }^{30}$ Simultaneamente com o protesto indígena realizava-se em Porto Rico a quarta rodada de negociações do tratado de livre comércio com EUA. A negociação do tratado enfrentava um momento crítico, pois o congresso norte-americano negava-se a assiná-lo em atenção à denuncias no tocante ao desrespeito aos direitos trabalhistas e sindicais na Colômbia. Nessa perspectiva, o movimento indígena destaca sua preocupação com a exploração dos recursos naturais e culturais do país, entrando a competir com o discurso político governamental que afirma que dito tratado é indispensável para estimular o desenvolvimento econômico do país.

${ }^{31}$ Sin acuerdo, indígenas reanudan marcha hacia Bogotá. Revista Semana, Colômbia, 21/11/2008.

${ }^{32}$ Continua la minga, continua el debate. El Liberal, Colômbia, 03/11/2008.
} 
O descontentamento indígena cresceu diante das respostas do presidente Uribe e incentivou a materialização da ameaça, a realização de uma marcha de protesto até Bogotá $^{33}$. Nesta marcha, realizada em novembro de 2008, o destino final deixou de ser o âmbito local - capitais estaduais - e atingiu a capital do país. Alcançar Bogotá, símbolo de poder político, traz à tona a existência de uma força social dinâmica. O capital simbólico acumulado e mobilizado durante essa marcha indica o dinamismo de um processo indígena encaminhado a superar as fronteiras que a política oficial colombiana empenhou-se em impor aos povos ancestrais ${ }^{34}$.

Mecanismos de desqualificação do protesto indígena foram acionados na tentativa de conter a realização da marcha. O presidente Uribe afirmou que esse protesto não era conseqüente porque desafiava os problemas de segurança que o país enfrenta. Aliás, acusou os indígenas de aproveitar a marcha para esconder interesses políticos.

No veo relación entre los problemas que están planteando y la marcha. Veo que la marcha lo que tiene es un objetivo político y como tal lo debían presentar, pero no montarle mentiras. Digan la verdad, digan que ustedes tienen un partido político y que quieren salir a marchar y a protestar, pero no le inventen embustes al país. Multitudinario congreso indígena en el camino. Inter Press Service, 15/09/2008 (grifos nossos).

Nas declarações do presidente Uribe destaca-se a prática rotineira de desqualificar o protesto, nesta ocasião acusando os indígenas de mentirosos e inventores de problemáticas. O uso pejorativo da denominação "político", no discurso governamental, atribui uma carga negativa e desqualificadora sobre o agir indígena. Não obstante, a categoria "político" assume um sinal positivo no desenrolar do protesto indígena. Para ilustração vejamos a contestação indígena:

Claro que nuestra Minga es Política con P [mayúscula], porque político es defender la acción de tutela de los derechos indígenas y colectivos; político es rechazar que se despedace el Estado social de derecho; político es defender el carácter de entidad territorial de todos los territorios indígenas y su gobierno autónomo propio [...] Político es oponernos al TLC [tratado de libre comercio]; político es rechazar los asesinatos, desapariciones, desplazamientos forzados, violencia y guerra; político es discrepar de la llamada seguridad democrática; político es defender las conquistas que hemos logrado en la Constitución [...]; político es defender la vida y la dignidad. Cien kilómetros de un largo camino. Inter Press Service, 18/09/2008 (grifos nossos).

$\mathrm{Na}$ intensidade do confronto discursivo os indígenas não temem arguir assumindo sua condição de sujeitos políticos. Expressam ainda que, a defesa dos direitos constitucionalmente outorgados não é atribuição exclusiva dos partidos políticos e que apesar da existência de partidos políticos indígenas, as reivindicações que incentivam o protesto indígena estão além dos interesses partidários. A empreitada

\footnotetext{
${ }^{33}$ Sin acuerdo, indígenas reanudan marcha hacia Bogotá. Revista Semana, Colômbia, 21/11/2008.

${ }^{34}$ A integração [dizimação] dos povos originários e a redução dos territórios indígenas são os traços mais marcantes dessa política. Segundo Gomez (2000), o estado colombiano continua exercitando uma dupla política de reprocessamento da integração. Isto é, no discurso, na esfera jurídica e política diz respeitar e reconhecer a diversidade étnica. Mas, na prática mediante seus aparatos e programas de desenvolvimento econômico absorve/integra a etnicidade que diz defender.
} 
consistente em levar uma multidão indígena até Bogotá não foi desanimada pelo ataque discursivo governamental.

15.000 indígenas aproximadamente mobilizaram-se através de 300 quilômetros de estradas. A marcha de protesto indígena evidenciou a existência de práticas políticas que visam mudar a estrutura de dominação. A "cerca simbólica" imposta aos indígenas é empurrada pela força do processo de reivindicação indígena. No âmbito das fronteiras simbólicas, Bogotá centro da tomada de decisões, foi atingida pela presença de uma marcha de protesto nutrida por uma multidão de indígenas. A marcha permitiu que o deslocamento das fronteiras simbólicas acontecesse. Os indígenas caucanos, historicamente limitados à vida de resguardo indígena, atravessaram essa fronteira simbólica e geográfica mediante mecanismos peculiares, porém eficazes de ação política.

Durante dois meses, outubro a novembro de 2008, os indígenas caucanos conseguiram criar fatos que viraram noticias, e desse modo conquistaram a atenção nacional e internacional. Conforme indica Gómez (2000) a força e persistência do poder étnico se evidenciam no âmbito dos fatos. Assim, criar fatos é um mecanismo de reprodução do poder étnico. O poder étnico requer do território, por isso, sua defesa constitui-se no pilar das suas reivindicações.

\section{Considerações finais}

No Estado de Cauca, sul da Colômbia, passeatas, bloqueio de estradas e marchas, articulam-se como estratégias de uma prática indígena que reflete descontentamento, contestação e protesto social. Antes de 1991 esse movimento acontecia, principalmente, no interior das fronteiras locais. Em 2008, a marcha de reclamo originou-se em diferentes localidades estaduais e terminou frente à sede do governo nacional em Bogotá, conseguindo mobilizar aproximadamente 15.000 indígenas. Destaca-se o poder de convocatória à marcha, apesar das tensões que existem entre os diferentes povos ali congregados.

No contexto nacional colombiano há diversos entraves para materializar o mandato constitucional de 1991, cientes disso, os indígenas adotaram modos peculiares de protesto e reivindicação política. As passeatas, o bloqueio de estradas e as marchas demonstraram serem mecanismos eficazes para chamar a atenção da sociedade envolvente. Nesses cenários de protesto o discurso apresenta-se como instrumento determinante para conferir-se legitimidade. Na disputa entre o discurso indígena e o discurso governamental dois termos são recorrentes: "mentira" e "política". A primeira palavra é acionada para indicar que uma das partes envolvida no conflito está faltando à verdade, no caso que nos ocupa vimos que quando as palavras não foram suficientes apelou-se às imagens de vídeo. Observou-se que graças a difusão dessas imagens o protesto indígena legitimou-se. O termo político, usualmente atingia de modo negativo o protesto indígena. Mas, no debate político, suscitado pela intensidade do protesto, os indígenas não temem o exercício dos direitos como sujeitos políticos. Declaram-se sabedores de que a defesa dos direitos constitucionalmente outorgados não é atribuição dos partidos políticos, são taxativos ao afirmar que seu processo de reivindicação indígena não fica atrelado a interesses partidários.

A eficácia dos atos de protesto aqui estudados radica no âmbito do simbólico. A prática política de protesto descrita neste trabalho é carregada de simbolismo. A marcha autodenominou-se "minga", durante seu desenrolar elementos centrais da identidade indígena foram explorados: o escudo indígena, a "guardia indígena", as bengalas de 
mando, a chirimía ${ }^{35}$, os rituais de limpeza com ervas para isolar as energias ruins. Não se tratou somente de demonstrar capacidade para criar noticias mediante as quais se denunciou o descaso o governamental diante das suas demandas. Mediante essa prática de protesto os indígenas caucanos colocam em alto relevo seu poder étnico.

Marchar até Bogotá demonstra não apenas capacidade organizativa para executar um evento de protesto com abrangência nacional, sobretudo indica maturidade política na apresentação e difusão das reivindicações indígenas. Observou-se capacidade organizativa e consciência social coletivas, reconhecimento do significado da reivindicação identitária e domínio do debate político no contexto nacional e estrangeiro. A marcha até a capital do país foi uma caminhada em direção ao poder político uma demonstração de ultrapassagem das fronteiras que encurralam aos indígenas numa Colômbia profunda ou nas regiões de refugio. Criaram-se fatos que viraram noticias, conquistou-se a visibilidade e legitimidade para sua luta. Os indígenas corroboraram sua capacidade para ir além dos seus próprios limites no processo de defesa e legitimação territorial. A incursão da marcha indígena pelo território nacional, apesar de ser uma aparição passageira, logrou a construção de uma imagem viva do índio, instaurou uma visão dos indígenas contemporâneos a partir deles mesmos, confirmando-se como uma realidade viva na Colômbia.

Essa prática de protesto indígena aqui explorada é entendida no âmbito de um processo histórico e cumulativo. Começou com Tama durante a colonização espanhola, virou pensamento étnico com Lame na década de 1900, materializa-se na década de 1970 com a política de recuperação de terras e a criação do CRIC, assume o caráter de disputa política no século XXI. A partir da defesa do território os indígenas aprenderam a capitalizar simbólica e politicamente o espaço aberto pela violência praticada pela força pública. A imagem dos indígenas sendo repelidos pela força pública usou-se para legitimar o processo de reivindicação étnica. A repressão estatal contra os indígenas foi eficazmente aproveitada para questionar a política de "seguridad democrática". Nos eventos de protesto em questão o governo Uribe fracassou na sua tentativa de negligenciar o potencial político desse movimento social. Os indígenas constataram sua força política e capacidade para criar mecanismos eficazes de protesto.

\section{Referências}

COLÔMBIA. Carta abierta al presidente Uribe. Popayán: 2008, 2 páginas.

Castillo, Luis Carlos. Etnicidad y nación: el desafío de la diversidad en Colombia. Cali: Universidad del Valle, 2007.

CHAVES, Christine. A marcha nacional dos sem-terra. Rio de Janeiro: Relume Dumará. 2000.

GOMEZ, Herinaldy. Poder étnico y reconocimiento de la diversidad cultural. In: De la Justicia y poder indígena. Popayán: editorial universidad del Cauca. 2000.

MACHADO, Absalón. Problemas agrarios colombianos. Bogotá: Siglo XXI. 1986.

MATOS, Maria Helena Ortolan. Processo de criação e consolidação do movimento pan-indígena no Brasil (1970-1980). Dissertação de mestrado em Antropologia, Universidade de Brasília, 1997.

RAPPAPORT, Joane. La política de la memoria. Interpretación indígena de la historia en los andes colombianos. Popayán: editorial Universidad del Cauca. 2000.

\footnotetext{
35 Grupo musical com cinco integrantes, interpretando música tradicional com flautas, tambores e instrumentos com cimentes.
} 
RUANO, Elizabeth. O cultivo da papoula na Colômbia: um estudo de caso sobre os agricultores familiares do Município de Silvia (Cauca). Universidade de Brasília: Dissertação de Mestrado em Agronegócios, 2008.

SÁNCHEZ, J. Etnia, poder y diferencia en los Andes septentrionales. Quito: Abya-yala. 1990. 